\title{
A Novel Structure of Blackbody Cavity Sensor for Continuous Measurement of Molten Steel Temperature
}

\author{
Zhi XIE, ${ }^{1)}$ Jiu ZHANG, ${ }^{1{ }^{*}}$ Guohui MEI, ${ }^{1)}$ Shumao ZHAO, ${ }^{11}$ Bin LIANG $^{2)}$ and Yuexin LIN ${ }^{21}$ \\ 1) College of Information Science and Engineering, Northeastern University, China, Mailbox 321 , Northeastern University, \\ Shenyang, Liaoning, 110819 China. $\quad$ 2) Taihe Metallurgical Measurement and Control Technologies Co., Ltd., No. 26, No. \\ 20 North Road, Economic and Technological Development Zone, Shenyang, Liaoning, 110024 China.
}

(Received on March 20, 2014; accepted on April 23, 2014)

\begin{abstract}
For continuous measurement of molten steel temperature, this work proposed a novel structure of blackbody cavity sensor to overcome the shortcomings of the traditional sensor. The traditional sensor had slow response speed and poor thermal shock resistance, which was due to its double layer tubes and thermal stress concentration in the closed bottom of an inner corundum tube respectively. The double layers included an outer protective tube of $\mathrm{Al}_{2} \mathrm{O}_{3}-\mathrm{C}$ refractory and the inner tube which formed the blackbody cavity and isolated the fume generated by the outer tube. The novel structure was composed of a measurement cavity of an $\mathrm{Al}_{2} \mathrm{O}_{3}-\mathrm{C}$ tube and a fume exhaust system. The fume exhaust system, including an inlet, an exhaust pipe and two outlets, eliminated the fume influence of obstructing the optical path. Furthermore, the fume exhaust system was based on the relationship between the fume and temperature distribution. Results showed that the fume formed below approximately $1320^{\circ} \mathrm{C}$, meaning the fume existed in and above the slag layer in the internal cavity of the sensor. The open bottom of the exhaust pipe should locate at the interface between the slag layer and molten steel to remove the fume. Additionally, the sensor should dip into molten steel up to $220 \mathrm{~mm}$ for high accuracy. It improved the response time from 340 to 240 seconds and enhanced the thermal cycling times from about 4 to beyond 10 times.
\end{abstract}

KEY WORDS: blackbody cavity; molten steel temperature; novel structural sensor.

\section{Introduction}

Molten steel temperature is a key parameter for casting speed control, improvement of the slab quality and production. Disposable thermocouple has measured the molten steel temperature over the years, which has a high dispersibility, rigorous running environment and is discontinuous measurement. ${ }^{1)}$ High temperature and strong erosion make it difficult to measure the molten steel temperature continuously, and scholars had done many works on it. The platinum-rhodium (Pt-Rh) thermocouple with a protective tube was used to measure the molten steel temperature continuously. $^{2-4)}$ However, due to high cost of the noble-metal thermocouple, it is difficult to be widely applied in industrial fields. On the other hand, a radiation thermometry had been adopted. Actually, a sensor is dipped into molten steel, and then reaches thermal equilibrium with the molten steel. It generates an infrared signal according to different temperatures that can be received by a probe for representing the temperature.

For continuous measurement of the molten steel temperature, the sensor should have excellent resistance to erosion, good thermal shock resistance and high thermal conductivity. $\mathrm{Al}_{2} \mathrm{O}_{3}-\mathrm{C}$ refractory has these merits and is used for the

* Corresponding author: E-mail: neu_jiu@126.com DOI: http://dx.doi.org/10.2355/isijinternational.54.1849 sensor, ${ }^{5,6)}$ but it generates fume which obstructs the optical path for measuring the temperature. Two main problems exist in measuring the molten steel temperature based on the infrared radiation (IR) theory: one measurement fluctuation caused by the fume and the other measurement error resulted from the change of the integrated effective emissivity. For reducing the fume influence, Han K. Park had used highly pure raw materials and high firing temperature to fabricate the sensor. ${ }^{7)}$ Despite the measures taken, they still couldn't absolutely eliminate the fume, which also led to the measurement fluctuation. Besides, the integrated effective emissivity of the measurement cavity would change during the measuring when the senor didn't form a blackbody cavity. Several radiation sensors had been developed to measure the molten steel temperature, but they didn't investigate the integrated effective emissivity, which might result in the measurement error. ${ }^{8)}$ Though a colorimetric temperature measurement method was taken to reduce the influence of the integrated effective emissivity, the measurement error also existed due to that the measurement cavity wasn't a grey body. ${ }^{9)}$

A blackbody cavity sensor (called as the traditional sensor) had been developed for continuously measuring the molten steel temperature to solve this problem, ${ }^{10,11)}$ which was composed of an anti-erosion tube of $\mathrm{Al}_{2} \mathrm{O}_{3}-\mathrm{C}$ refractory (outer tube) and a high purity corundum tube with a closed bottom (inner tube) used to prevent the fume and formed a 
blackbody cavity. To form the blackbody cavity, the sensor should dip into the molten steel with a certain depth up to $250 \mathrm{~mm}$ in practice. This method achieved continuous and accurate measurement of the molten steel temperature, but there still existed some shortcomings of temperature response latency and poor thermal shock resistance. Response latency comes from the slow heat transfer of the double layer tubes. And the poor thermal shock resistance is due to thermal stress concentration at the closed bottom of the inner tube. In other words, the closed bottom is easy to damage with the rapid temperature change from room temperature to molten steel temperature.

The aim of the present work is to develop a novel structure of the blackbody cavity sensor to measure the molten steel temperature continuously, which has a fast response speed and good thermal shock resistance. The sensor eliminates the fume influence through the fume exhaust system which is on the basis of studying the fume distribution. Besides, the study investigates the operating characteristics of the sensor, such as the dipping depth, $\mathrm{N}_{2}$ flow rate for removing the fume, measurement accuracy, temperature response and thermal shock resistance.

\section{Qualitative Description of the Sensor}

Figure 1 shows the novel structure of the blackbody cavity sensor (new sensor) for measuring the molten steel temperature continuously, which is composed of a special processor, an IR probe, $\mathrm{Al}_{2} \mathrm{O}_{3}-\mathrm{C}$ tube, an exhaust pipe $(99 \%$ ceramic corundum) with an open bottom, an inlet and two outlets. Measurement principles of the new sensor are as followed: firstly, the sensor is dipped into molten steel with a certain depth and reaches the thermal equilibrium with the molten steel; then, the bottom of $\mathrm{Al}_{2} \mathrm{O}_{3}-\mathrm{C}$ tube forms the blackbody cavity which generates an infrared signal according to different temperatures; finally, the probe receives the infrared signal and the processor calculates the temperature.

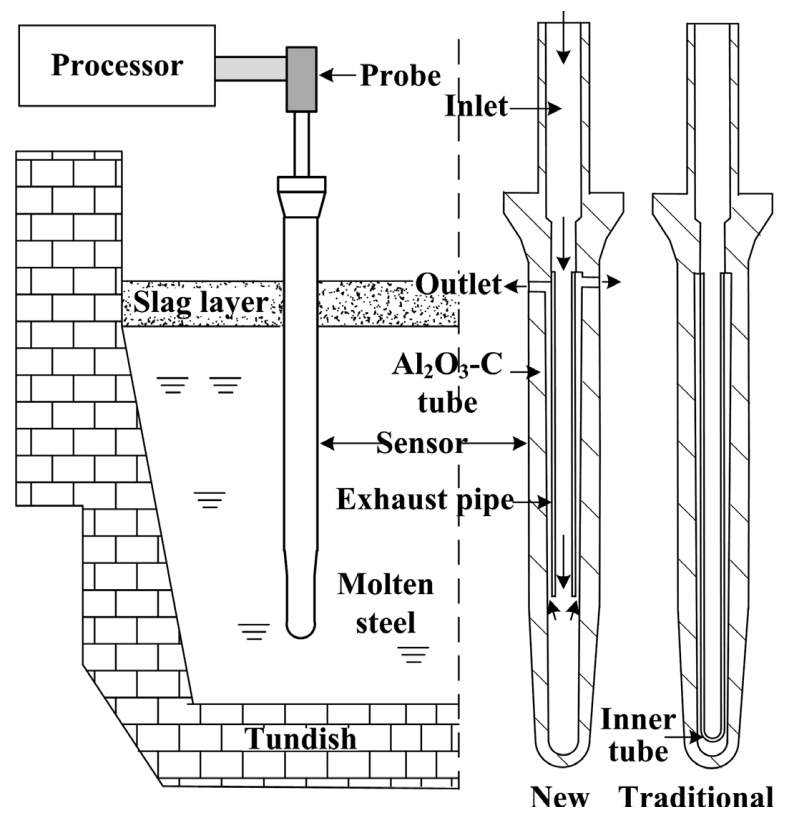

Fig. 1. A novel structure of the blackbody cavity sensor (new) and the traditional sensor.
The integrated effective emissivity of this cavity is approximately equal to 1 , which leads to high accuracy of the sensor. Compared with the blackbody cavity of the traditional sensor formed by the corundum tube with a closed bottom, the $\mathrm{Al}_{2} \mathrm{O}_{3}-\mathrm{C}$ tube directly forms the blackbody cavity for the new sensor. Meanwhile, the heat transfer process in the traditional sensor include double layers $\left(\mathrm{Al}_{2} \mathrm{O}_{3}-\mathrm{C}\right.$ tube and corundum tube) while the new sensor is only a single layer $\left(\mathrm{Al}_{2} \mathrm{O}_{3}-\mathrm{C}\right.$ tube), which resulted in that the new sensor has a faster response speed than the traditional sensor. Due to the fact that the fume generated by the $\mathrm{Al}_{2} \mathrm{O}_{3}-\mathrm{C}$ tube obstructs the optical path of the temperature measurement, the fume exhaust system is proposed. According to the previous research, the fume distribution depended on the temperature distribution. More specifically, the fume zone only exists under a certain temperature. The fume is removed as the arrows: a gas enters into the internal cavity from the inlet and passes the exhaust pipe, then takes away the fume out of the sensor through the outlets. For avoiding the oxidation of the $\mathrm{Al}_{2} \mathrm{O}_{3}-\mathrm{C}$ tube, the gas should be non-oxidizing gas, such as $\mathrm{N}_{2}$ and $\mathrm{Ar}$, and $\mathrm{N}_{2}$ is used in this paper. To ensure the fume is completely removed from the sensor, the open bottom of the exhaust pipe should be below the fume zone, its specific location is studied. For obtaining the high measurement accuracy, the $\mathrm{N}_{2}$ flow rate for removing the fume and the dipping depth for forming the blackbody cavity are investigated.

\section{Design of the Sensor}

\subsection{Location of the Open Bottom}

For eliminating the fume influence, it is necessary to determine the specific location of the open bottom of the exhaust pipe, which is related to the distribution and physicochemical characteristic of the fume. The fume originates from the raw materials' impurities of the $\mathrm{Al}_{2} \mathrm{O}_{3}-\mathrm{C}$ tube as shown in Table 1. Raw materials of the $\mathrm{Al}_{2} \mathrm{O}_{3}-\mathrm{C}$ tube are fused alumina powders $(75 \%)$, graphite flakes $(20 \%)$, additives $(5 \%)$ and phenolic resin binder. These impurities, converting into transparent vapors at a high temperature, don't affect the temperature measurement, which has been confirmed by the experiment. However, the transparent vapors convert into the fume at lower temperature, and then obstruct the optical path of the temperature measurement. In other words, the fume distribution is associated with the temperature in the internal cavity of the sensor. The relationship of the fume and temperature distribution was measured in a high temperature furnace as shown in Fig. 2. The furnace was heated to $1550^{\circ} \mathrm{C}$ and kept for $5 \mathrm{~h}$, and then the fume generated by the $\mathrm{Al}_{2} \mathrm{O}_{3}-\mathrm{C}$ tube would adhere on the corundum tube. According to the temperature distribution, the fume would attach to the different height regions of the corundum tube. The temperature distribution was measured

Table 1. Chemical compositions of the basic raw materials (in wt.\%).

\begin{tabular}{cccccccc}
\hline & $\mathrm{Al}_{2} \mathrm{O}_{3}$ & $\mathrm{C}$ & $\mathrm{CaO}$ & $\mathrm{SiO}_{2}$ & $\mathrm{MgO}$ & $\mathrm{Fe}_{2} \mathrm{O}_{3}$ & $\mathrm{Na}_{2} \mathrm{O}$ \\
\hline Fused alumina & 99.24 & - & - & 0.1 & - & 0.14 & 0.39 \\
Graphite flake & 0.22 & 97.57 & 0.13 & 0.60 & 0.11 & 0.28 & - \\
\hline
\end{tabular}


by a Pt-Rh thermocouple (type B).

Figure 3 represents the relationship of the fume and temperature distribution, the $\mathrm{X}$-axis refers to the distance from

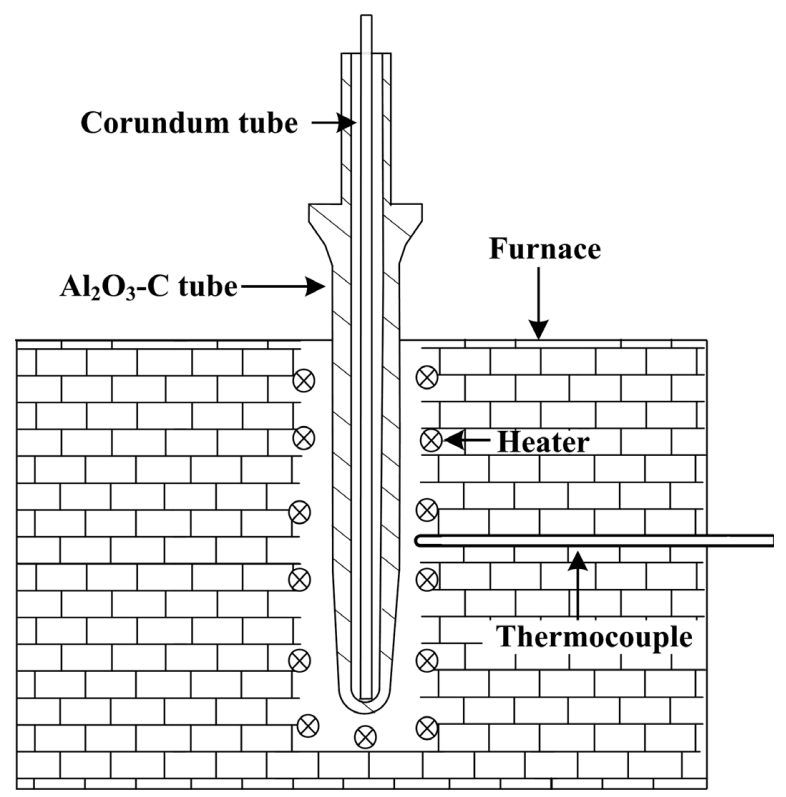

Fig. 2. Schematic diagram for measuring the fume distribution.

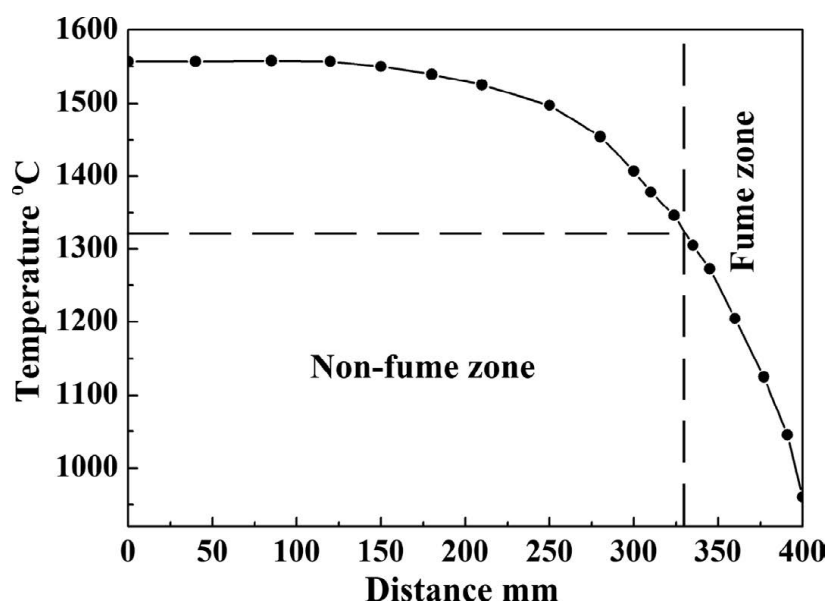

Fig. 3. Relationship between the fume and temperature distribution. the measuring point to the internal bottom of the $\mathrm{Al}_{2} \mathrm{O}_{3}-\mathrm{C}$ tube. It turned out that there was no fume attaching to the corundum tube when the temperature was higher than approximately $1320^{\circ} \mathrm{C}$, which implied that the formation temperature of the fume was low to $1320^{\circ} \mathrm{C}$. Microstructure and compositions of the fume were analyzed by scanning electron microscope (SEM) and energy diffraction spectrum (EDS) respectively as shown in Fig. 4. The fume showed as granular and fibrous which would obstruct the optical path for temperature measurement. And compositions involved $\mathrm{O}, \mathrm{Na}, \mathrm{Al}$ and $\mathrm{Si}$, leading to that the fume had low vaporization temperature and formed condensates at a low temperature. The characteristic peak of $\mathrm{Au}$ correlated the spraying $\mathrm{Au}$ for the electric conduction of the sample. On the basis of the fume distribution in the internal cavity, the open bottom of the exhaust pipe should locate in a region that has a higher temperature than $1320^{\circ} \mathrm{C}$ for removing the fume.

In fact, the specific location of the open bottom in the internal cavity of the sensor is investigated when the sensor continuously measures the molten steel temperature. To obtain the fume distribution in the internal cavity, its temperature distribution is measured by a Pt-Rh thermocouple during the industrial operation. Figure 5 depicts the temperature distribution in the internal cavity, and the $\mathrm{X}$-axis refers

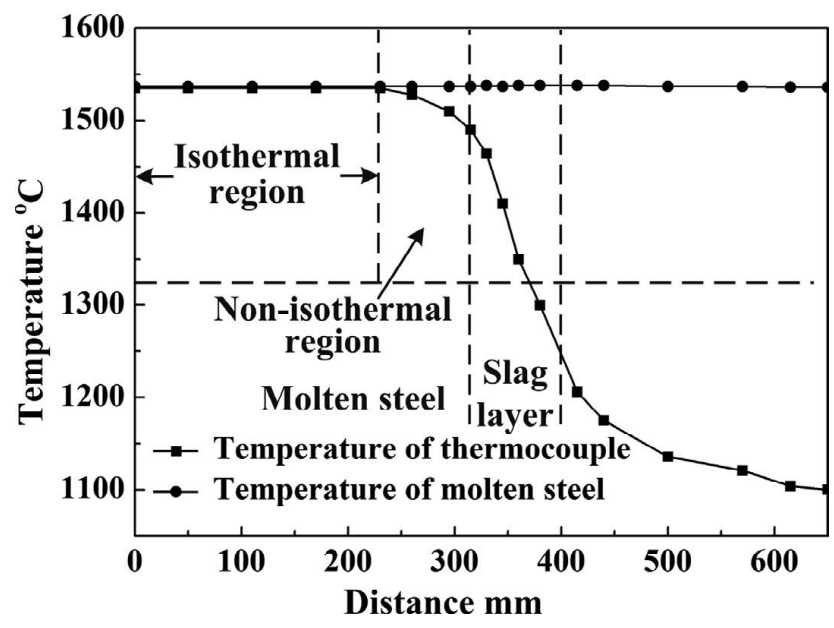

Fig. 5. Temperature distribution in the internal cavity of the sensor.

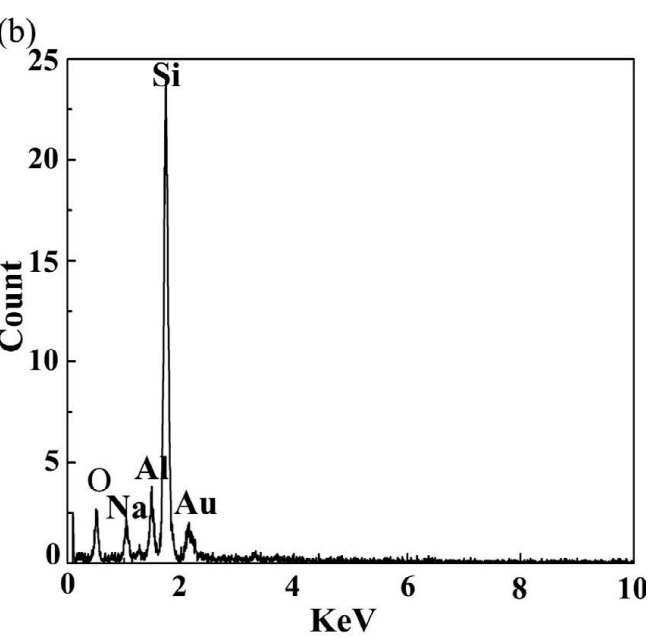

Fig. 4. Microstructure and compositions of the fume (SEM and EDS, respectively). 
to the distance from the internal bottom of the sensor to the measuring point. According to the relationship between the temperature and fume distribution, the formation of the fume zone was about $370 \mathrm{~mm}$ away from the internal bottom. Its actual position was in the slag layer, the slag layer was about $90 \mathrm{~mm}$ and its thickness varied in different continuous casting. Besides, the molten steel temperature varied according to the different steel grades, which would lead to the change of the temperature distribution in the internal cavity. Thus, to ensure that the open bottom is always below the fume zone, the open bottom should locate at the interface between the slag layer and molten steel in the internal cavity.

\subsection{Dipping Depth of the Sensor}

To measure the molten steel temperature accurately, the sensor should dip into molten steel with a certain depth for forming a blackbody cavity. The dipping depth includes an isothermal length and a non-isothermal length, which is studied by the theoretical analysis firstly. And then it is decided by industrial experiments on the basis of the theoretical result. A certain length of the isothermal region makes the integrated effective emissivity of the cavity be approximate to 1 . According to the blackbody cavity structure as shown in Fig. 6, the relationship between the relative length of isothermal region $(H / R)$ and the integrated effective emissivity $\left(\varepsilon_{e, A_{0}}\right)$ was calculated by the integral equation method, ${ }^{12,13)}$ following the Eqs. (1)-(2).

$$
\varepsilon_{e}\left(x_{0}\right)=\varepsilon+(1-\varepsilon) \int_{\text {cavity }} \varepsilon_{e}(x) d^{2} F_{x_{0}, x}
$$

where $\varepsilon_{e}\left(x_{0}\right)$ and $\varepsilon_{e}(x)$ are the local effective emissivity at $x_{0}$ and $x$ in the cavity respectively, $\varepsilon$ is the wall emissivity, and $d^{2} F_{x_{0}, x}$ is the angle factor between infinitesimal areas at $x_{0}$ and $x$.

$$
\varepsilon_{e, A_{0}}=\frac{\int_{A_{0}} \varepsilon_{e}(x) d F_{x, D} d A_{x}}{\int_{A_{0}} d F_{x, D} d A_{x}}
$$

where $\varepsilon_{e, A_{0}}$ is the integrated effective emissivity from $A_{0}$ to the detector, $d F_{x, D}$ is the angle factor from the infinitesimal area at $x$ within $A_{0}$ to the detector, and $A_{0}$ is the target region.

$H$ is the isothermal region length, and $R$, the radius of the blackbody cavity, is $12.5 \mathrm{~mm}$. $R_{0}$, the opening radius of the

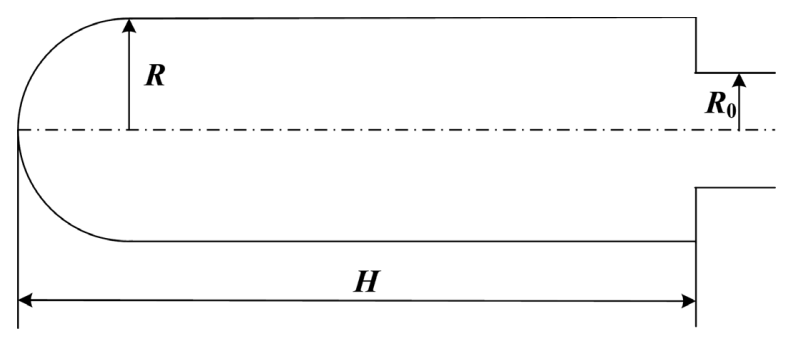

Fig. 6. Blackbody cavity structure of the sensor.

Table 2. Relationship between $H / R$ and $\varepsilon_{e, A_{0}}$.

\begin{tabular}{ccccccc}
\hline$H / R$ & 3 & 4 & 5 & 6 & 7 & 8 \\
\hline$\varepsilon_{e, A_{0}}$ & 0.9925 & 0.9953 & 0.9968 & 0.9977 & 0.9983 & 0.9987 \\
\hline
\end{tabular}

blackbody cavity, is $7.5 \mathrm{~mm}$. The diameter of the target region $\left(A_{0}\right)$ is $5 \mathrm{~mm}$, meeting the demand of the luminous flux for the detector. And the wall emissivity of $\mathrm{Al}_{2} \mathrm{O}_{3}-\mathrm{C}$ tube is $0.75 .^{14)}$ The calculation results are illustrated in Table 2, which indicated that the integrated effective emissivity increased with increasing the relative length.

In order to make the measurement error be less than $1^{\circ} \mathrm{C}$ at $1550^{\circ} \mathrm{C}$, the integrated effective emissivity had to be more than 0.9974 , which was calculated by the following Eqs. (3)-(6). ${ }^{15)}$

$$
T_{t}=T_{i} \sqrt[4]{1 / \varepsilon_{e, A_{0}}}
$$

When the measurement error caused by the integrated emissivity variation is $\leq 1^{\circ} \mathrm{C}$,

$$
\begin{array}{r}
T_{t}-T_{i} \leq 1 \\
\varepsilon_{e, A_{0}} \geq\left(T_{t}-T_{i}\right)^{4} / T_{t}
\end{array}
$$

When $T_{t}$ is $1550^{\circ} \mathrm{C}$,

$$
\varepsilon_{e, A_{0}} \geq 0.9974
$$

where $T_{t}$ is the real temperature of molten steel and $T_{i}$ is the indicated temperature by the detector.

According to the relationship between $H / R$ and $\varepsilon_{e, A_{0}}$ in Table 2, the relative length $(H / R)$ should be up to 6 . And the isothermal region length should be greater than $75 \mathrm{~mm}$ for this cavity. Due to the reason that there existed the nonisothermal region of the sensor below the molten steel surface, it should be attached to the dipping depth. For instance, the non-isothermal region length was about $90 \mathrm{~mm}$ as shown in Fig. 5.

However, the non-isothermal region length is frequently changed, which is related to the slag layer state, such as the thickness and composition. To be specific, the slag layer affects the temperature of the molten steel surface. Effect of the slag layer on the non-isothermal region length was investigated by thermal analysis. The relationship between the surface temperature of molten steel and the non-isothermal region length (NITR Length) is represented in Fig. 7. The molten steel temperature was $1550^{\circ} \mathrm{C}$. Point A represents the thermal analysis result of the non-isothermal region length $(98 \mathrm{~mm})$ as shown in Fig. 5, which is consistent with the measured non-isothermal region length (about $90 \mathrm{~mm}$ ). Following the change of the surface temperature from 1200 to $1525^{\circ} \mathrm{C}$, the non-isothermal region length varies from 117 to $90 \mathrm{~mm}$ according to the thermal analysis result. The temperature of the molten steel surface was above $1200^{\circ} \mathrm{C}$ in practice, so the non-isothermal region length is less than $117 \mathrm{~mm}$. Therefore, the dipping depth should be approximately equal to $192 \mathrm{~mm}$ according to the theory analysis for forming a blackbody cavity, including the lengths of the isothermal region and the non-isothermal region, which is described as shown in Fig. 8.

In practice, the actual emissivity of the $\mathrm{Al}_{2} \mathrm{O}_{3}-\mathrm{C}$ wall is influenced by the temperature, surface roughness and microstructure, which would lead to the change of the integrated effective emissivity. Meanwhile, the actual temperature distribution of the internal cavity might change according to different conditions of continuous casting, which also has an influence on the integrated effective emissivity. Therefore, 


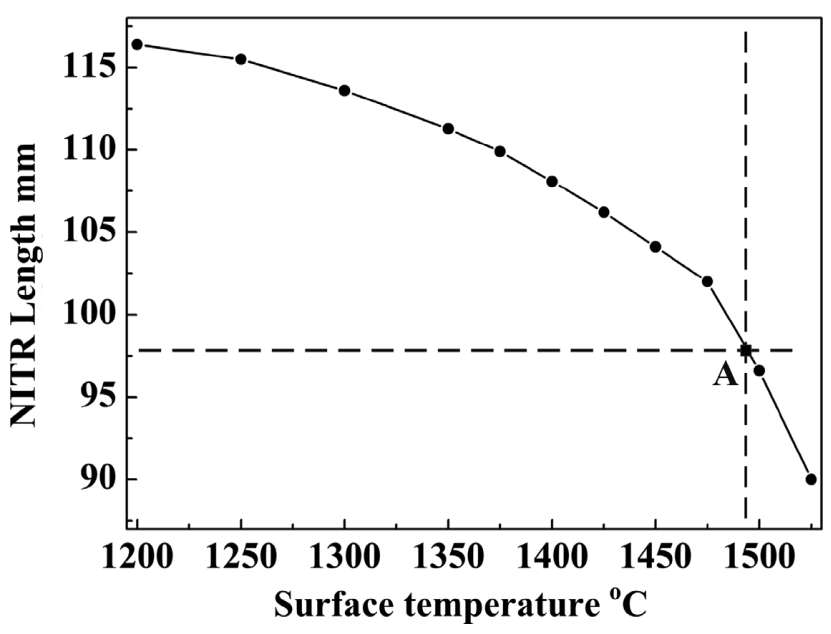

Fig. 7. Variation of non-isothermal region length (NITR Length) with the surface temperature of molten steel.

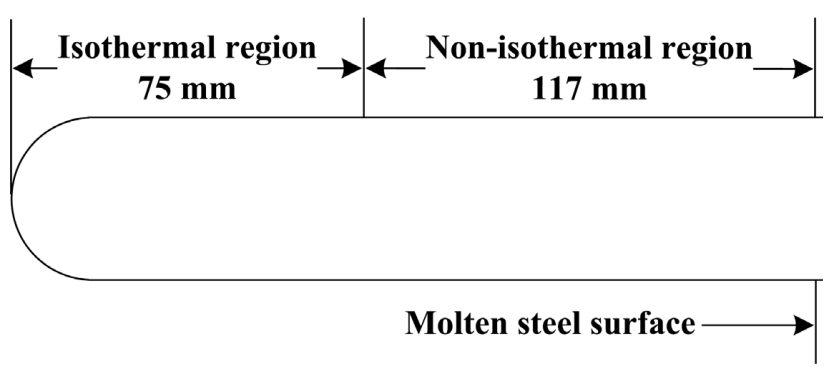

Fig. 8. Dipping depth of the cavity design for the novel sensor.

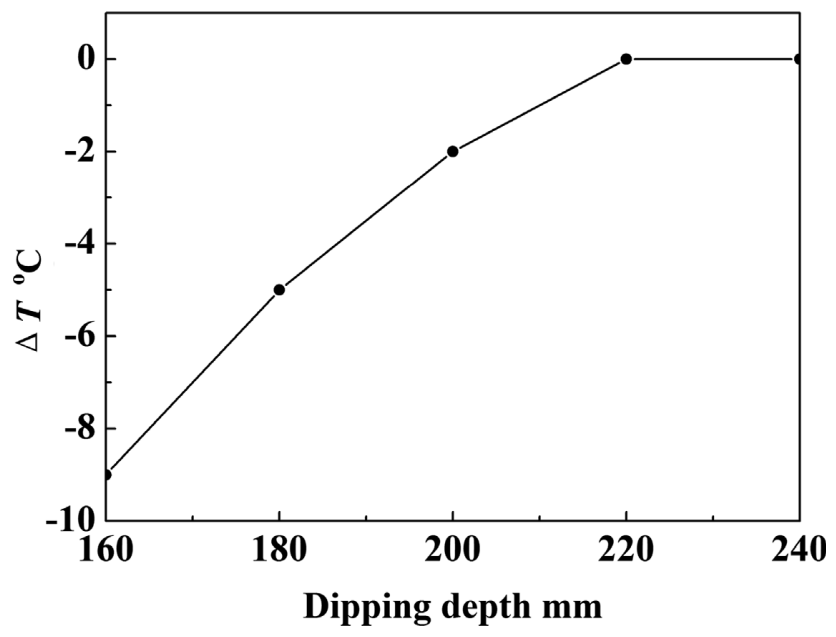

Fig. 9. Relationship between the measurement error $(\Delta T)$ and the dipping depth.

it is necessary to optimize the theoretical result of the dipping depth. And this paper investigated it by the industrial experiment. The experimental conditions were that the molten steel temperature was about $1530^{\circ} \mathrm{C}$ and the slag layer was about $70 \mathrm{~mm}$, these were similar as shown in Fig. 5. Figure 9 represents a relationship between the measurement error $(\Delta T)$ and the dipping depth. It indicated that the dipping depth of the industrial experiment was larger than the theoretical result, which may be associated with that the actual emissivity of the material is lower than the theoretical value. So the sensor should be dipped into the molten steel up to $220 \mathrm{~mm}$ for a high accuracy.
Table 3. Variation of the measurement error $(\sigma T)$ with the $\mathrm{N}_{2}$ flow rate.

$\mathrm{N}_{2}$ flow rate (ml/min) $200 \quad 400 \quad 800 \quad 1600 \quad 3200 \quad 6400 \quad 12800$

$\begin{array}{llllllll}\sigma T\left({ }^{\circ} \mathrm{C}\right) & 0 & 0 & 0 & 0 & -1 & -2 & -4\end{array}$

\section{3. $\mathbf{N}_{2}$ Flow Rate}

In order to remove the fume from the internal cavity of the sensor, a suitable flow rate of $\mathrm{N}_{2}$ is necessary. A high flow rate may cool the measurement cavity, which will result in that the measurement temperature is lower than the real temperature. The influence of the $\mathrm{N}_{2}$ flow rate on the measurement error is studied. Table 3 shows the variation of the measurement error $(\sigma T)$ with the $\mathrm{N}_{2}$ flow rate under the conditions depicted as in Fig. 6, the dipping depth is about $310 \mathrm{~mm}$ and the open bottom of the exhaust pipe is $300 \mathrm{~mm}$ away from the internal bottom. As the $\mathrm{N}_{2}$ flow rate is below $1600 \mathrm{ml} / \mathrm{min}$, there isn't measurement error. With the flow rate increased to $12800 \mathrm{ml} / \mathrm{min}$, the measurement error increased with the $\mathrm{N}_{2}$ flow rate from -1 to $-4^{\circ} \mathrm{C}$. The error derives from the destruction of the isothermal cavity, which results from that the isothermal region length isn't enough and the integral emissivity is less than 1 . In addition, the minimum flow rate hasn't high requirement due to that the fume volume is little and can be taken away easily. In practice, the measurement error caused by the $\mathrm{N}_{2}$ flow rate also related to the distance between the open bottom and the internal bottom. As the distance increased, the $\mathrm{N}_{2}$ flow rate could be higher.

\section{Performances Test}

\subsection{Measurement Accuracy}

Measurement accuracy is a key parameter for the temperature sensor, which is checked by a control experiment in Angang Steel Co., Ltd (in Anshan, China). The second-class $\mathrm{Pt}-\mathrm{Rh}$ thermocouple is used to evaluate the measurement accuracy of the novel structural sensor. And the thermocouple has a protective tube of $99 \%$ corundum. Schematic of the control experiment for the measurement accuracy is illustrated in Fig. 10. The thermocouple and the sensor were dipped into molten steel in a tundish. The dipping depth of the sensor was about $300 \mathrm{~mm}$ and the thermocouple was protected by the $\mathrm{Al}_{2} \mathrm{O}_{3}-\mathrm{C}$ protective tube that was the same with the $\mathrm{Al}_{2} \mathrm{O}_{3}-\mathrm{C}$ tube of the sensor. The location of the open bottom of the exhaust pipe is $300 \mathrm{~mm}$ away from the internal bottom of the sensor. And the $\mathrm{N}_{2}$ flow rate was $1600 \mathrm{ml} / \mathrm{min}$ for removing the fume. Then, the sensor was dipped into the molten steel when the temperature of the thermocouple was stable. Figure 11 shows the temperature curves of the new sensor and the thermocouple. It indicated that the measurement results of the new sensor and the thermocouple were similar and their error was less than or equal to $3{ }^{\circ} \mathrm{C}$. This is associated with that the sensor has formed a blackbody cavity for the temperature measurement with a dipping depth of $300 \mathrm{~mm}$. In addition, the temperature response of the sensor is faster than the thermocouple during the changing process of the ladle, which is associated with that the thermocouple has a more heat transfer of the corundum tube. Besides, the measurement accuracy of the sensor 


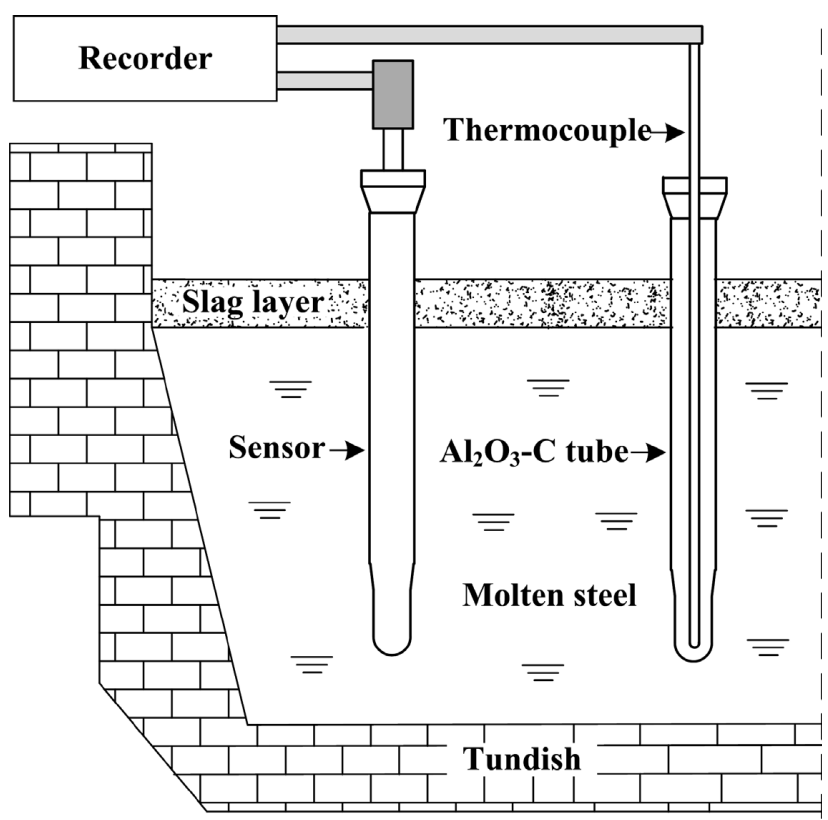

Fig. 10. Experimental device for checking the measurement accuracy of the novel structural sensor.

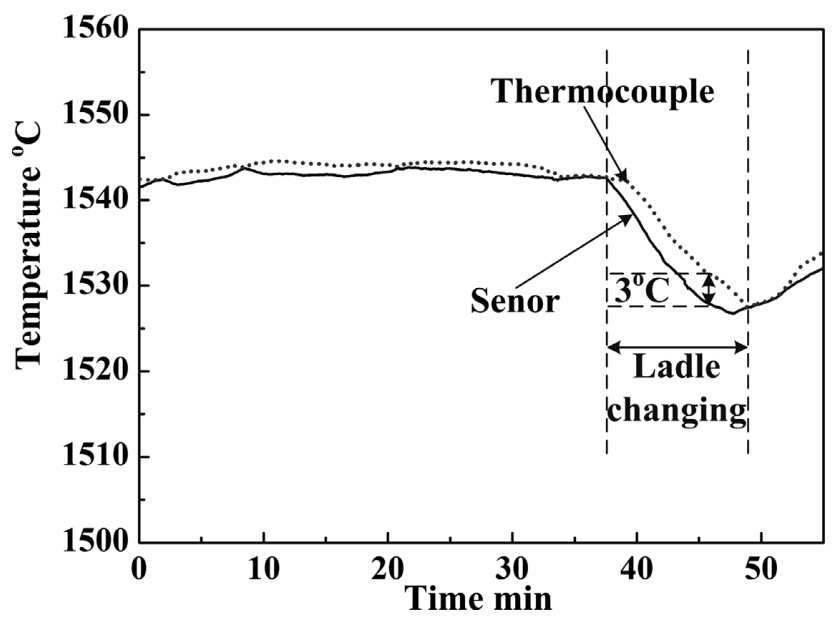

Fig. 11. Accuracy test of the novel structural sensor. is equivalent to that of conventional one, which is depended on the blackbody cavity theory. Thus, the blackbody cavity sensor with the novel structure has a high accuracy, which meets the demand of industrial operation.

\subsection{Temperature Response}

Comparing with the traditional sensor for continuous temperature measurement in molten steel, the novel structural sensor has faster temperature response. The response time of the traditional sensor is about 5-6 min. Figure 12 depicts two typical temperature curves of the new and traditional sensors. It indicated that the new sensor remarkably improved the response time from 340 to 240 seconds, which was associated with that the new sensor had not a ceramic corundum tube with a closed bottom for isolating the fume. And the new sensor had faster heat transfer. In addition, the new sensor directly made use of the $\mathrm{Al}_{2} \mathrm{O}_{3}-\mathrm{C}$ tube to form the blackbody cavity for measuring the temperature, but the traditional sensor formed the blackbody cavity through the ceramic corundum tube with a closed bottom. The material emissivity of the $\mathrm{Al}_{2} \mathrm{O}_{3}-\mathrm{C}$ refractory is higher than the ceramic corundum, which results in that the new sensor is easier to form a blackbody cavity than the traditional sensor.

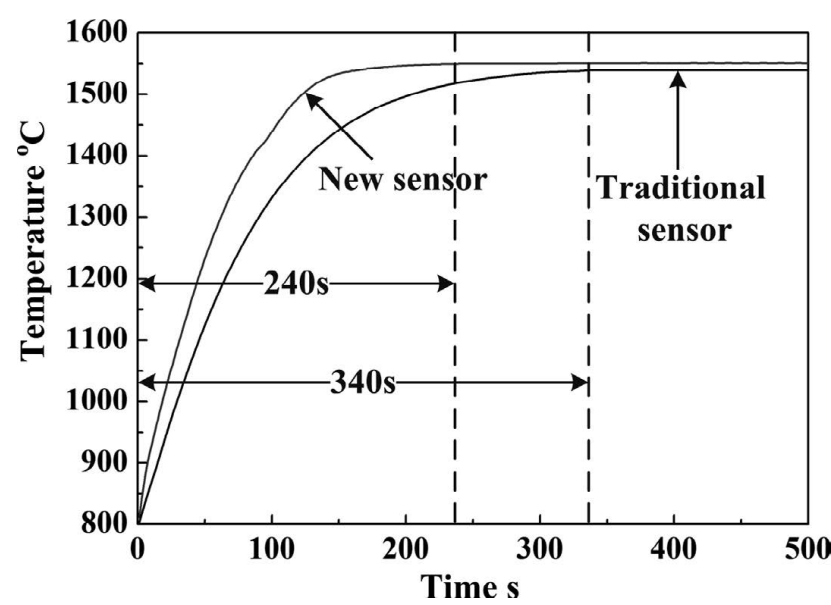

Fig. 12. Temperature response curves of the new and traditional sensors.

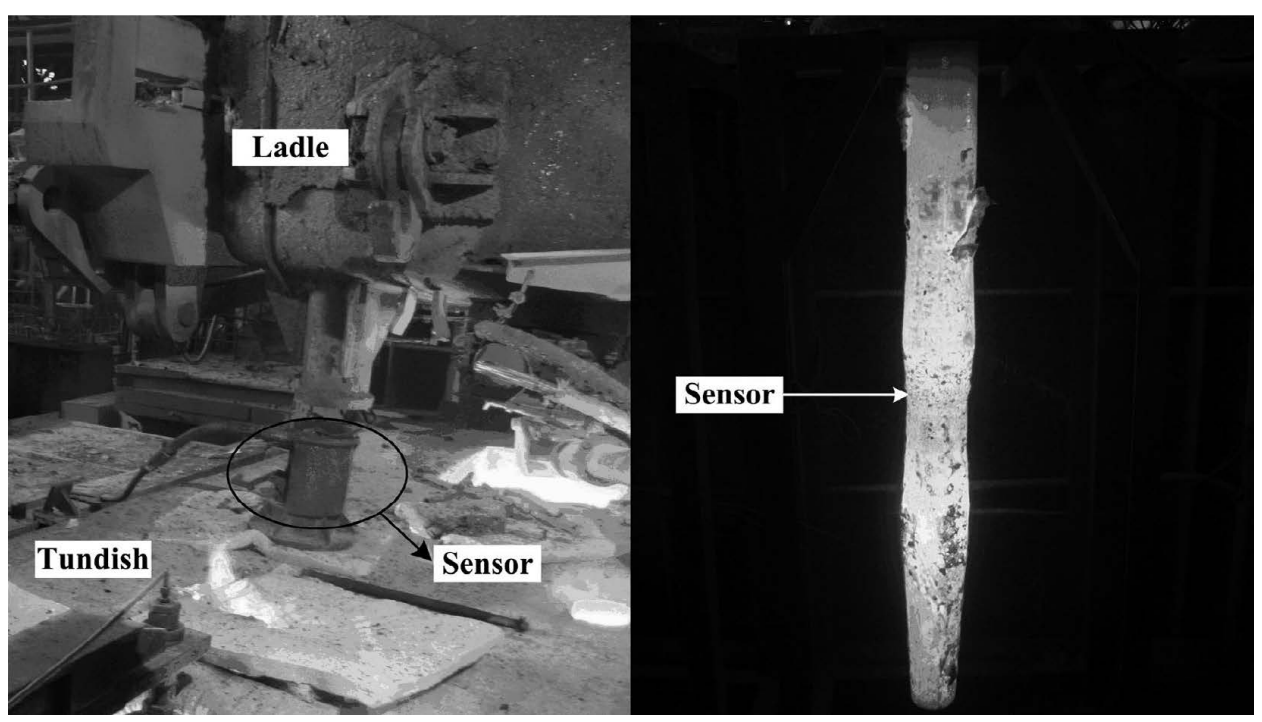

Fig. 13. Application of the new structural sensor in a steel factory. 
Table 4. Thermal cycling times of the new sensor.

\begin{tabular}{cccccc}
\hline Traditional sensor & 3 & 4 & 5 & 5 & 4 \\
\hline New sensor & $>10$ & $>10$ & $>10$ & $>10$ & $>10$
\end{tabular}

\subsection{Thermal Shock Resistance}

The novel structural blackbody cavity sensor has been applied in about 20 steel factories (shown in Fig. 13) more than one year, which has well satisfied the need of industry operation. In detail, it not only has an equal accuracy with the traditional sensor, but also has a faster temperature response. Particularly, the thermal shock resistance of the new sensor is a better performance, which is tested in this paper and showed as in Table 4. The thermal shock resistance was tested from room temperature to $1500^{\circ} \mathrm{C}$, and the sensor was heated by the molten steel and cooled in air. It indicated that the novel structural sensor improved the thermal cycling times from about 4 to beyond 10 times, significantly enhancing the reliability. The reason is that the exhaust pipe hasn't thermal stress concentration of the closed bottom, and it works in relatively lower temperature compared with the inner tube of the traditional sensor.

\section{Conclusion}

In this paper, a novel structure of blackbody cavity sensor for continuous measurement of molten steel temperature was proposed. The sensor had a fast temperature response and good thermal shock resistance, which was composed of a measurement cavity of $\mathrm{Al}_{2} \mathrm{O}_{3}-\mathrm{C}$ tube and a fume exhaust system. The fume exhaust system removed the fume generated by the $\mathrm{Al}_{2} \mathrm{O}_{3}-\mathrm{C}$ tube, preventing the fume from obstructing the optical path of temperature measurement.

Based on the relationship between the fume and temperature distribution, the fume formed below approximately $1320^{\circ} \mathrm{C}$, meaning the fume zone located in and above the slag layer in the internal cavity of the sensor. To eliminate the fume influence, the open bottom of the exhaust pipe should locate at the interface between the slag layer and molten steel. For high accuracy, the sensor should dip into molten steel up to $220 \mathrm{~mm}$ to form the blackbody cavity.

Compared with the traditional sensor, the novel structural sensor improved the response time from 340 to 240 seconds and enhanced the thermal cycling times from about 4 to beyond 10 times.

\section{Acknowledgements}

The authors gratefully acknowledge the financial support received from the National Natural Science Foundation of China (No. 2013ZCX01) and Fundamental Research Funds for Central Universities of China (No. 110404029).

\section{REFERENCES}

1) B. Silver: US Patent, 3306783, (1967)

2) M. Nakano, K. Mori, Y. Hiraiwa, S. Shima and Y. Nakamura: US Patent, 4984904, (1991).

3) M. Kendall: US Patent, 8033717, (2011)

4) R. Michael Phillippi: US Patent, 5069553, (1991).

5) W. E. Lee and S. Zhang: Int. Mater. Rev., 44 (1999), 77.

6) J. Zhang, G. Mei, S. Zhao and Z. Xie: ISIJ Int., 54 (2014), 553.

7) H. K. Park: US Patent, 5302027, (1994).

8) S. Shima, T. Kondo, I. Sakaguchi, K. Gomyo and S. Inoue: JP Patent, 07-012650, (1995).

9) J. Raposo Barbosa, L. Fernando Marzano, F. Correa Martins, M. O. Xavier Silva and A. da Silva Gomes: US Patent, 7690841, (2010).

10) P. Van Der Maat and E. Hanse: US Patent, 7445384, (2008).

11) Z. Xie, R. Chen and H. Meng: US Patent, 6846105, (2005).

12) Z. Chu, R. E. Bedford, W. Xu and X. Liu: Appl. Opt., 28 (1989), 1826.

13) R. E. Bedford, C. K. Ma, Z. Chu, Y. Sun and S. Chen: Appl. Opt., 24 (1985), 2971.

14) N. Schmitt, A. Burr, Y. Berthaud and J. Poirier: Mech. Mater., 34 (2002), 725.

15) L. Michalski, K. Eckersdorf, J. Kucharski and J. McGhee: Temperature Measurement, 2nd ed., John Wiley \& Sons Ltd, Chichester, (2001), 187. 